\title{
Fonologia do português: quando duas variedades divergem
}

\author{
Camila Witt ULRICH (D) \\ Universidade Federal do Rio Grande do Sul (UFRGS)
}

\section{RESUMO}

Vigário apresenta diferenças fonológicas entre o português brasileiro (PB) e o europeu (PE) na forma de dez tópicos relacionados a processos nos níveis lexical e pós-lexical. De modo geral, a autora mostra que o português europeu apresenta processos produtivos nos níveis mais altos da hierarquia prosódica, e não em constituintes menores, como o segmento ou a sílaba. Por esse motivo, temos um grande número de reduções vocálicas em posições átonas, por exemplo. Enquanto isso, os processos do português brasileiro ocupam-se, em geral, com os níveis mais baixos da hierarquia, os quais são puramente fonológicos. Exemplos são o preenchimento de posições vazias para boa-formação silábica ou o menor número de reduções vocálicas em relação ao PE. Embora as duas variedades apresentem semelhanças em relação à fonologia lexical, em níveis mais precoces, elas exibem perfis fonológicos distintos em relação à fonologia pós-lexical.

EDITADO POR

Raquel Freitag

AVALIADO POR

Luiz Schwindt

DATAS

Recebido: 04/07/2020 Aceito: $25 / 07 / 2020$ Publicado: 05/08/2020

COMO CITAR

Ulrich, C. W. (2020). Fonologia do português: quando duas variedades divergem. Revista da Abralin, v. 19, n. 2, p.

\section{ABSTRACT}

Vigário presents phonological differences between Brazilian (BP) and European Portuguese (EP) through ten topics related to processes in the lexical and post-lexical levels. In general, the author shows that European Portuguese presents productive processes in the higher levels of the prosodic hierarchy, and not in the lower constituents, as the segment or the syllable. For this reason, we have a great number of vowel reductions in unstressed positions, for example. Meanwhile, the processes in Brazilian Portuguese apply, in general, in the lower levels of the hierarchy, which are purely phonological. As examples we can mention the filling of empty positions due to syllabic well-formedness or the smallest number of vowel reductions in relation to EP. Although both varieties present similarities in 


\section{REVISTA DA ABRALIN}

relation to the lexical phonology, in earlier levels, they exhibit distinct phonological profiles in relation to the post-lexical phonology.

\section{PALAVRAS-CHAVE}

Fonologia. Português brasileiro. Português europeu.

\section{KEYWORDS}

Phonology. Brazilian Portuguese. European Portuguese.

Como parte da série Abralin ao vivo - Linguists online, Marina Vigário - professora da Universidade de Lisboa/Portugal - profere a conferência Diferenças fonológicas entre as variedades brasileira e europeia do português: revisão, discussão e implicações, mediada pelo professor Luiz Carlos Schwindt (UFRGS) no dia 26 de junho de 2020.

Vigário aborda de forma clara e sucinta diferenças fonético-fonológicas entre o português europeu (PE) e o português brasileiro (PB) com base no comportamento de dez processos distintos e traz implicações das diferenças apontadas para a configuração fonológica das duas variedades. De modo geral, a ideia central da autora consiste em mostrar que o PE tende a ser produtivo em níveis mais altos da hierarquia prosódica, enquanto o PB apresenta mais processos para satisfazer condições de constituintes prosódicos mais baixos.

Como ponto de partida, Vigário assume a existência de (i) processos lexicais, os quais podem fazer referência à informação morfológica e são obrigatórios, e (ii) processos pós-lexicais, que dependem unicamente de informação fonológica e têm aplicação opcional. Assume também pressupostos da Geometria de Traços, da Fonologia Métrica, da Fonologia Autossegmental e da Fonologia Entoacional.

A autora inicia sua análise admitindo que o sistema vocálico subjacente é o mesmo nas duas

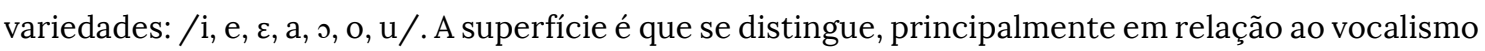
átono. No PB, a saliência da vogal tônica é menos evidente, pelo fato de a língua apresentar menos reduções vocálicas em posições átonas e, como consequência, menos graus de contrastes no sistema. O PE, pelo contrário, tende a reduzir ou apagar as vogais átonas com maior frequência, o que causa uma maior saliência da vogal tônica e, portanto, do acento lexical.

Em relação às diferentes propostas existentes para a atribuição de acento primário ${ }^{1}$, Vigário assume que as duas variedades podem ser explicadas por sistemas distintos. A autora mostra que, no $\mathrm{PB}$, parecem ser preponderantes princípios fonológicos e rítmicos, enquanto o PE apres enta evidências mais fortes para a explicação de base morfológica, o que a conferencista chama de "morfologização do acento". Apesar de a maior parte das análises concordar sobre a influência da morfologia 


\section{REVISTA DA ABRALIN}

na análise de verbos, um ponto de forte de discordância entre muitos autores está relacionado ao tratamento conjunto ou separado de verbos e não verbos no que diz respeito ao acento. Nesse sentido, a conclusão de Vigário nos leva a acreditar na adequação de uma proposta unificada para o PE, mas separada para o PB.

O papel de fatores prosódicos ou morfológicos atuantes sobre o acento primário nas duas variedades pode mostrar também diferentes padrões de acento secundário. O acento secundário em PB apresenta um padrão binário bastante consistente à esquerda do acento primário; o ritmo ternário surge, na maioria das vezes, quando o número de sílabas pretônicas é ímpar. No PE, por outro lado, estudos experimentais mostram que o acento secundário ocorre tipicamente na primeira sílaba da palavra prosódica, podendo incluir o clítico (ex. em familiaridáde / èm familiaridáde) (CASTELO, 2006).

Em relação à manifestação das proeminências na estrutura entoacional, Vigário afirma que, em $\mathrm{PB}$, temos um acento tonal por palavra, e, por vezes, até mais de um acento, a depender do tamanho da palavra, como em catalogadora (VIGÁRIO; FERNANDES-SVARTMAN, 2010). O PE não apresenta tantos acentos tonais e tem uma linha entoacional mais reta, com menos alternâncias entre tons altos e tons baixos. As oscilações, portanto, não marcam palavras, mas posições extremas de IP.

Ambas as variedades de português analisadas apresentam ritmo misto, mas de modos distintos. Segundo Vigário, associadas às propriedades silábicas, o PB apresenta propriedades de tipo moraico, enquanto o PE apresenta ritmo acentual. Essa distinção pode ser bem representada por dados de percepção: falantes de português europeu são capazes de discriminar e identificar as duas variedades ao escutarem dados manipulados e deslexicalizados, os quais apresentam apenas as propriedades rítmicas do contínuo sonoro (FROTA; MARTINS; VIGÁRIO, 2002).

O princípio básico de organização silábica é similar nas duas variedades; a forma de preenchêla, contudo, também é distinta. O PB tende a preencher slots vazios para a obtenção de boa-formação silábica (ex. pneu $\rightarrow p[I] n e u$ ). Como evidência adicional à trazida pela conferencista, acrescentamos, ainda, que a obediência a princípios silábicos em PB permite o apagamento de vogais mediais em algumas palavras proparoxítonas (ex. fósf[o]ro fósfro), já que o reagrupamento dos segmentos mantém o padrão paroxítono. O PE geralmente não preenche esses mesmos espaços e, como já comentado, permite apagamentos que não causam reorganização dos segmentos (ex. $m$ [i]nistro $\rightarrow$ mnistro). Quando o slot vazio de alguma sílaba é preenchido em PE, isso pode ser explicado como um requerimento de constituintes mais altos na hierarquia prosódica, e não da sílaba.

Ainda em relação à produtividade na fonologia de níveis mais baixos da hierarquia, o PB apresenta muitas evidências para o tratamento do pé métrico, como os abaixamentos datílico (ex. esquel $[e]$ to $\rightarrow$ esquel[ $[\varepsilon]$ tico) e espondaico (ex. $d[\mathrm{o}] c e \rightarrow d[\mathrm{o}] \mathrm{cil}$ ), os acentos rítmicos e o fenômeno de truncamento (ex. neurose $\rightarrow$ neura). No PE, não há evidências tão claras e robustas para esse domínio. Por outro lado, o PE apresenta evidências de diversos tipos para o domínio da palavra prosódica, incluindo o truncamento (ex. telemóvel $\rightarrow$ móvel). No PB, a evidência relacionada ao contraste entre formas tônicas e átonas é menor do que em PE e a distinção entre clíticos e palavras prosódicas é menos clara. 


\section{REVISTA DA ABRALIN}

Em relação à resolução de antagonismos acentuais, o PB pode apresentar deslocamento ou apagamento (ex. redatór-chefe $\rightarrow$ rèdator-chefe) - os mesmos processos que acontecem na frase fonológica (ex. café quente $\rightarrow$ càfe quente), o que mostra que os princípios rítmicos são mais valorizados do que o acento de palavra. No PE, há mais preservação do acento principal em sua posição original, comprovando a hipótese de maior morfologização do acento.

Por fim, o último tópico abordado é o da ressilabificação. A autora mostra que o PB parece não ter um domínio de aplicação tão claro para aplicação do fenômeno. Na variedade europeia, a ressilabificação marca fronteiras de IP.

A fim de sintetizar a fala da conferencista, elaboramos um quadro geral comparativo entre as características das duas variedades apresentadas.

\begin{tabular}{lll}
\hline Processos & Português brasileiro & Português europeu \\
\hline 1. Sistema vocálico & menos reduções & mais reduções \\
2. Acento primário & explicação fonológica/mista & explicação morfológica \\
3. Acento secundário & mais regular e frequente & menos frequente \\
4. Acento tonal & relacionado à palavra & relacionado ao IP \\
5. Ritmo & misto: silábico/moraico & misto: silábico/acentual \\
6. Sílaba & menos violações de boa-formação & mais violações de boa-formação \\
7. Pé métrico & muitas evidências & poucas evidências \\
8. PWd e clíticos & menor número de evidências e me- & muitas evidências e alto contraste \\
& nor distinção entre palavras e clíti- & entre palavras e clíticos \\
9. Variação acentual & cos & \\
10. Ressilabificação & prevalência de padrões rítmicos & prevalência de acentos lexicais \\
& sem domínio específico & domínio: IP
\end{tabular}

QUADRO 1 - Síntese das diferenças fonético-fonológicas entre as variedades brasileira e europeia Fonte: da autora (2020)

Embora as duas variedades apresentem semelhanças em relação à fonologia lexical mais profunda, a conclusão de Vigário é de que as duas variedades apresentam perfis fonológicos distintos. Análises do português brasileiro mostram um perfil mais produtivo em domínios mais baixos da hierarquia prosódica, como a sílaba e o pé. Já o português europeu apresenta fonologia produtiva em domínios mais altos da hierarquia. Por essa razão, o PB opta, por exemplo, por preservar ou inserir segmentos, enquanto o PE preserva estruturas dos enunciados. Assim, estamos tratando de duas variedades da mesma língua, as quais são paralelas na fonologia lexical mais profunda, mas distintas em relação à fonologia produtiva e pós-lexical.

A conferência é rica em exemplos e menções a estudos sobre os mais variados processos fonológicos presentes nas variedades brasileira e europeia do português. A análise da professora Marina Vigário é clara e entusiasma todos os estudantes e pesquisadores da área. 


\title{
REVISTA DA ABRALIN
}

\author{
REFERÊNCIAS
}

CASTELO, Adelina. A proeminência secundária rítmica no Português Europeu: uma proposta. In: XXI Encontro Nacional da Associação Portuguesa de Linguística. Lisboa: APL, 2006, p. 261-272.

DIFERENÇAS fonológicas entre as variedades brasileira e europeia do português: revisão, discussão e implicações. Conferência apresentada por Marina Vigário e conduzida por Luiz Carlos Schwindt [s.l., s.n], 2020. 1 vídeo (1h 59min 15s). Publicada pelo canal da Associação Brasileira de Linguística. Disponível em: https://www.youtube.com/watch?v=TEyFSisDRWk\&t=1177s. Acesso em 27 jun de 2020).

FROTA, Sonia; MARTINS, Fernando; VIGÁRIO, Marina. Language discrimination and rhythm classes: Evidence from Portuguese. In: Proceedings of Speech Prosody 2002, Aix en Provence, 2002, p. 315-318.

MAGALHÃES, José. Main stress and secondary stress in Brazilian and European Portuguese. In: WETZELS, W. L; MENUZZI, S.; COSTA, J. (eds) The handbook of Portuguese linguistics. Wiley-Blacwell, 2016, p. 107-124.

VIGÁRIO, Marina; FERNANDES-SVARTMAN, Flaviane. A atribuição tonal em compostos no Português do Brasil. In: BRITO, A. M.; SILVA, F.; VELOSO, J.; FIÉIS, A. (Org.). XXV Encontro Nacional da Associação Portuguesa de Linguística. Textos Seleccionados. Porto: Associação Portuguesa de Linguística, 2010, p.769-786. 